\title{
Long term doxorubicin cardiotoxicity in childhood: non-invasive evaluation of the contractile state and diastolic filling
}

\author{
G HAUSDORF, * G MORF, G BERON, R ERTTMANN, K WINKLER, \\ G LANDBECK, E W KECK* \\ From the Departments of ${ }^{*}$ Paediatric Cardiology and Paediatric Haematology and Oncology, University \\ Hospital, Hamburg, Federal Republic of Germany
}

SUMMARY Cardiac performance was evaluated at least two years after doxorubicin treatment in childhood in 55 patients without overt congestive cardiomyopathy. None of the patients had received mediastinal irradiation. Computer-assisted analysis of digitised echocardiograms showed impaired rapid diastolic filling and an increased change of dimension between minimal cavity dimension and mitral valve opening. This impairment of diastolic function was related to the cumulative dose of doxorubicin. In contrast when angiotensin II was infused to increase the afterload the end systolic pressure-length and stress-shortening relation indicated normal left ventricular systolic function. But during baseline conditions the end systolic wall stress was significantly increased in patients in whom the cumulative dose of doxorubicin exceeded $360 \mathrm{mg} / \mathrm{m}^{2}$.

Doxorubicin is a highly effective antineoplastic agent, but its use is limited by a cumulative doserelated cardiomyopathy. ${ }^{1}$ There is still considerable concern about long term cardiac performance after antineoplastic treatment with doxorubicin, particularly in childhood. ${ }^{2-4}$ The cumulative dose of doxorubicin should be limited to $450 \mathrm{mg} / \mathrm{m}^{2}$ body surface area. ${ }^{1}$ But some patients develop cardiomyopathy even at lower cumulative doses, particularly when there are additional risk factors such as mediastinal irradiation. ${ }^{1}$ Doxorubicin can cause specific ultrastructural changes in the myocardium at much lower cumulative doses, without altering left ventricular function. ${ }^{5-7}$ This suggests that even relatively low cumulative doses of doxorubicin can cause subclinical damage.

The standard indices of left ventricular performance-the ejection phase indices-cannot discriminate between abnormal contractility and altered loading conditions (preload and afterload). ${ }^{8-10} \mathrm{Al}-$ though the extent of myocardial fibre shortening is often used as an index of contractility, it is really a reflection of the interaction between contractile state,

Requests for reprints to Dr G Hausdorf, Deutsches Herzzentrum Berlin, Augustenburger Platz 1, D-1000 Berlin 65, Federal Republic of Germany.

Accepted for publication 13 February 1988 preload, and afterload. ${ }^{9-11}$ The slope of the end systolic pressure-length relation, however, is an index of the contractile state that is independent of load. ${ }^{12-14}$ The end systolic stress-shortening relations seem to be even more sensitive measures of impaired contractility. ${ }^{9-11}$

Chronic anthracycline cardiotoxicity can alter diastolic function too. Recently Mortensen et al reported haemodynamic and structural findings suggestive of restrictive endomyocardial disease after treatment with anthracyclines. ${ }^{15}$ Altered diastolic properties were also recognised by computer-assisted analyses of digitised echocardiograms. ${ }^{16}{ }^{17}$ These reports show that diastolic function must be studied when the effect of chronic doxorubicin cardiotoxicity is being examined.

We evaluated long term cardiac performance after doxorubicin treatment in childhood. We studied the contractile state by analysing the end systolic pressure-length and stress-shortening relations and we used computer-assisted analysis of digitised echocardiograms to evaluate diastolic filling.

\section{Patients and methods}

PATIENT GROUP

We studied 55 patients who had been treated with doxorubicin for childhood malignancies. In all 
patients doxorubicin was part of a multiple drug regimen (leukaemia: doxorubicin, vincristine, methylprednisolone, cyclophosphamide, 6-mercaptopurine, arabinoside-C; osteosarcoma: doxorubicin, methotrexate, bleomycin, actinomycin-D, cyclophosphamide; Ewing's sarcoma and soft tissue sarcoma: doxorubicin, vincristine, cyclophosphamide, actinomycin-D, bleomycin).

All patients were in complete remission after the end of antineoplastic treatment. None of them had been treated by irradiation of the mediastinum. The cumulative dose of doxorubicin ranged from 31 to $656 \mathrm{mg} / \mathrm{m}^{2}$ (mean (SD) $273(152) \mathrm{mg} / \mathrm{m}^{2}$ ). All patients had been off treatment for at least two years (range $2 \cdot 1$ to 10.4). We selected those who had been off treatment for the longest time from among patients who had had similar cumulative doses of doxorubicin. After five patients had been excluded from the study (see Results) patients were arbitrarily divided into three groups according to their cumulative dose of doxorubicin: group $1(\mathrm{n}=20)$, $<180 \mathrm{mg} / \mathrm{m}^{2}$; group $2(\mathrm{n}=13), 180-360 \mathrm{mg} / \mathrm{m}^{2}$; group $3(\mathrm{n}=17),>360 \mathrm{mg} / \mathrm{m}^{2}$.

\section{CONTROL GROUP}

The control group consisted of 30 healthy volunteers aged $18-30 .^{8}$ None had a history of cardiovascular disease. Physical examination, electrocardiography, $M$ mode echocardiography, and cross sectional echocardiography showed no abnormalities. None of them was taking medications.

\section{ECHOCARDIOGRAMS}

Echocardiograms were performed with Picker 80C Echoview ultrasound imaging device with a $3.5 \mathrm{MHz}$ and $2.25 \mathrm{MHz}$ transducer. The $M$ mode echocardiograms were recorded at the tip of the mitral valve leaflets in the standard position at a paper speed of $100 \mathrm{~mm} / \mathrm{s}^{18}$ The transducer was held in position for all measurements. All echocardiograms were recorded by one echocardiographer to eliminate interobserver variability. A carotid pulse tracing was recorded simultaneously with the $M$ mode echocardiogram. It was corrected for pulse transmission delay by aligning it with the aortic valve echocardiogram.

\section{EVALUATION OF THE CONTRACTILE STATE Measurement of end systolic pressure}

Systolic and diastolic blood pressure were measured by a Dinamap 845 Vital Signs Monitor (Criticon Inc.). This device has been shown to estimate central aortic pressure accurately over a wide range of pressure and independently of cardiac index, systemic vascular resistance, heart rate, and body surface area. ${ }^{19}$ The end systolic pressure $\left(P_{e s}\right)$ was estimated by the method of Stefadouros et al ${ }^{20}$ b产 linear interpolation of the height of the dicrotic notchof the indirect carotid pulse tracing. ${ }^{19} 20$

\section{Study protocol}

All examinations were performed in patients resting in the semisupine position. The patients relaxe for at least 10 minutes before the examination? Intravenous atropine $(0.01 \mathrm{mg} / \mathrm{kg})$ was given before the examination, to reduce reflex cardiac slowing 0 After baseline recordings the blood pressure was slowly increased by the infusion of angiotensin $I \overrightarrow{\mathrm{d}}$ $(0.5-3.5 \mu \mathrm{g} / \mathrm{min})$. We attempted to increase systolic blood pressure to $30 \mathrm{~mm} \mathbf{~ g}$ above baseline values? During the increase in blood pressure we made several simultaneous recordings of the $M$ mode echocardiogram, carotid pulse tracing, and arteriat blood pressure. We obtained the informed consent of all patients or their parents. The study protocol was approved by the local committee for human research

\section{Measurements and calculation}

We took the mean of three consecutive cardiac cyclesp Data points were excluded when the heart rate varied by more than 10 beats per minute from baseline: values. $^{8-10}$ The end diastolic internal left ventricular dimension $\left(D_{e d}\right)$ was measured at the start of the $Q R \&$ complex of the electrocardiogram and the end sys 5 tolic left ventricular dimension $\left(\mathrm{D}_{\mathrm{es}}\right)$ and posterio wall thickness $\left(P W_{e s}\right)$ were measured at end ejectio (assessed from the time corrected carotid pulse tracings). Ejection time (ET) was measured from the $\overrightarrow{\overrightarrow{0}}$ carotid pulse tracing. The end diastolic left ven 3 tricular dimension was corrected for differences of body surface area (BSA) according to ${ }^{21}$ :

$$
D_{\text {ed (corr) }}=D_{\text {ed }} \times(B S A)^{-1 / 3} \text {. }
$$

Fractional shortening (FS) was calculated as:

$$
F S=\frac{D_{e d}-D_{e s}}{D_{e d}} \times 100 \% \text {. }
$$

Mean fibre shortening velocity $\left(\mathrm{VCF}_{\text {mean }}\right)$ as:

$$
\mathrm{VCF}_{\text {mean }}=(\mathrm{FS} / \mathrm{ET}) \times 10 \mathrm{~s}^{-1} \text {. }
$$

End systolic meridional wall stress $\left(\sigma_{\mathrm{es}}\right)$ was cal $\mathrm{F}$. culated according to the method of Brodie et al ${ }^{22}$ : N

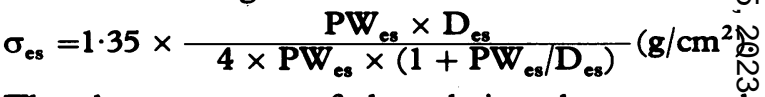
The slopes $a_{1}$ to $a_{3}$ of the relations between end systolic pressure and dimension $\left(\mathbf{P}_{\mathrm{es}}-\mathbf{D}_{\mathrm{es}} \text { relation }\right)_{\mathrm{d}}$ end systolic wall stress and fractional shortening $\left(\sigma_{\mathrm{e}}-\mathrm{FS}\right.$ relation), and end systolic wall stress an $\$$ mean fibre shortening velocity $\left(\sigma_{\mathrm{es}}-\mathrm{VCF}\right.$ relation were calculated according to the following equations? $P_{e s}-D_{e s}$ relation: $P_{e s}=a_{1} \times D_{e s}+b$

$\sigma_{\mathrm{ea}}-$ FS relation: $\mathrm{FS}=\mathrm{a}_{2} \times \sigma_{\mathrm{es}}+\mathrm{b}$

$\sigma_{\mathrm{es}}-\mathrm{VCF}$ relation: $\mathrm{VCF}=\mathrm{a}_{3} \times \sigma_{\mathrm{es}}+\mathrm{b}$ 


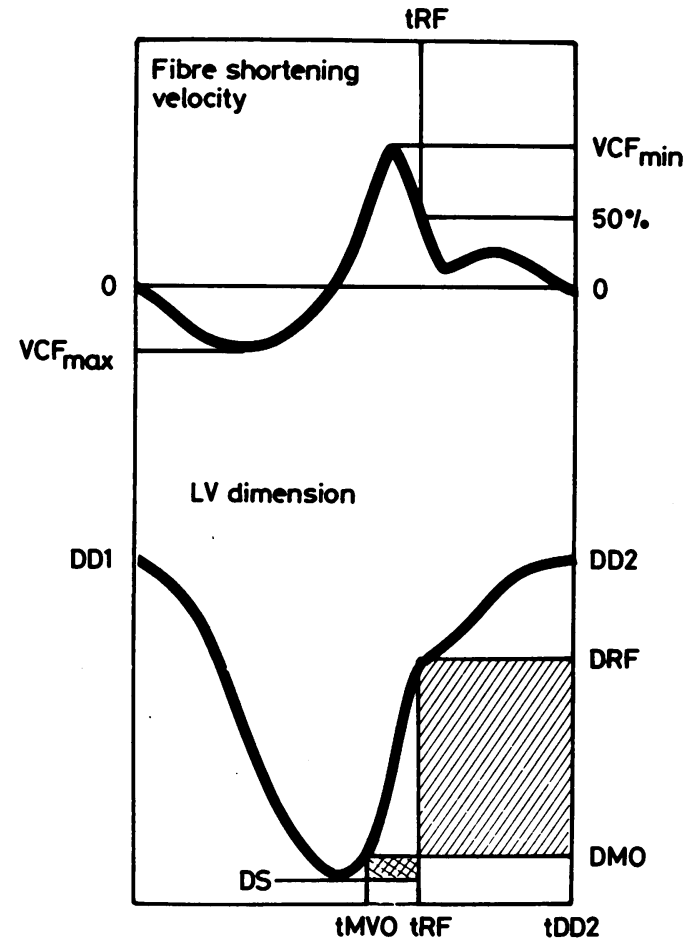

Fig 1 The instantanous left ventricular ( LV) internal dimension (lower curve) and its first derivative, the fibre shortening velocity (upper curve). DD1, end diastolic dimension at the beginning of the cardiac cycle; DD2, end diastolic dimension at the end of the cardiac cycle; $D S$, minimal left ventricular dimension; DMO, dimension at mitral valve opening; $D R F$, dimension at the end of rapid diastolic filling (point at which the normalised fibre shortening velocity had decreased to $50 \%$ of its peak value); $t M O$, time of mitral valve opening; $t R F$, time of the end of rapid diastolic filling; $t D D 2$, end of cardiac cycle; $V C F_{\text {max }}$, maximal fibre shortening velocity; $V C F_{\text {min, minimal fibre }}$ shortening velocity or maximal fibre lengthening rate.

\section{EVALUATION OF DIASTOLIC FUNCTION Computed-assisted analyses}

We used only good quality echocardiograms for computer-assisted analysis. The $\mathbf{M}$ mode echocardiograms were manually digitised with a Cardio 200 computer (Kontron Image Analysis). Three consecutive cardiac cycles were analysed and the mean was used for further calculations. The following were measured:

Measurement of time intervals-Time intervals were measured from the beginning of the $Q$ wave. The interval between minimal cavity dimension and mitral valve opening ( $t D S-M O$ ) was measured from the point at which the fibre shortening velocity curve crossed zero to the time of mitral leaflet separation (fig 1)..$^{2324}$

Measurement of dimensions and changes in dimen-
sion-The end diastolic left ventricular dimension (DD) was measured at the beginning of the first $Q$ wave of the cardiac cycle being analysed. Left ventricular dimension at aortic valve closure was taken as the end systolic dimension $\left(\mathrm{D}_{\mathrm{es}}\right)$. The maximal normalised fibre lengthening rate $\left(V L R_{\max }\right)$ was measured as the maximum of the first derivative of the left ventricular internal dimension curve that was standardised according to the instantaneous left ventricular dimension..$^{23}$ Minimal cavity dimension (DS) was measured at the point where the first derivative of the instantaneous left ventricular dimension curve crossed zero.

The change of dimension between minimal cavity dimension and mitral valve opening was defined $\operatorname{as}^{2324}$ :

$$
\mathrm{dDS}-\mathrm{MO}=\frac{\mathrm{DMO}-\mathrm{DS}}{\mathrm{DD} 2-\mathrm{DS}} \times 100 \%
$$

where DMO is the dimension at mitral valve opening; DS, minimal cavity dimension; and DD2, end diastolic dimension at the end of the cardiac cycle.

The end of rapid diastolic filling was defined as that point where the fibre shortening velocity had decreased to $50 \%$ of its peak value (fig 1). ${ }^{25}$ The change of dimension with rapid diastolic filling (dRF) was calculated as:

$$
\mathrm{dRF}=\frac{\mathrm{DRF}-\mathrm{DMO}}{\mathrm{DD} 2-\mathrm{DMO}} \times 100 \%
$$

where DRF is the dimension at the end of rapid diastolic filling; DS, minimal cavity dimension; DMO, dimension at mitral valve opening; and DD2 end diastolic dimension at the end of the cardiac cycle.

\section{STATISTICAL ANALYSIS}

Linear regression analysis was performied to calculate the slope values of the individual relations between end systolic pressure and dimension, end systolic wall stress and fractional shortening, and end systolic wall stress and mean velocity of fibre shortening. At least five data points were available in all patients and controls. The three patient groups and the control group were compared by analysis of variance with the SAS-program and the differences between two groups were tested by Duncan's multiple range test.

To eliminate the influence of different ages (and so differences of body surface area and heart rate) and different time intervals between end of treatment and investigation, analysis of covariance was performed with the covariates "age at investigation" and "time interval between end of treatment and investigation"; differences between the adjusted means were tested by a $t$ test matrix. A p value of $<0.05$ was regarded as statistically significant. 
Table 1 Mean (SD) baseline haemodynamic function

\begin{tabular}{|c|c|c|c|c|}
\hline & Group 1 & Group 2 & Group 3 & Control \\
\hline 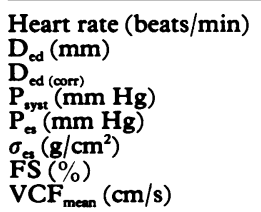 & $\begin{array}{c}81(16) \\
44(4 \cdot 4) \\
40(2 \cdot 5) \\
116(11) \\
84(12) \\
49(11) \\
34(4 \cdot 3) \\
1 \cdot 2(0 \cdot 20)\end{array}$ & $\begin{array}{l}76(19) \\
48(7 \cdot 6) \\
40(4 \cdot 9) \\
125(15) \\
92(18) \\
56(28) \\
34(6 \cdot 5) \\
1 \cdot 2(0 \cdot 24)\end{array}$ & $\begin{array}{c}74(17) \\
48(5 \cdot 5) \\
40(3 \cdot 8) \\
117(9) \\
85(11) \\
59(21) \\
31(5 \cdot 2) \\
1 \cdot 1(0 \cdot 19)\end{array}$ & $\begin{array}{l}63(10) \\
48(3 \cdot 5) \\
40(2 \cdot 2) \\
121(7) \\
89(9) \\
50(10) \\
34(2 \cdot 6) \\
1 \cdot 1(0 \cdot 12)\end{array}$ \\
\hline
\end{tabular}

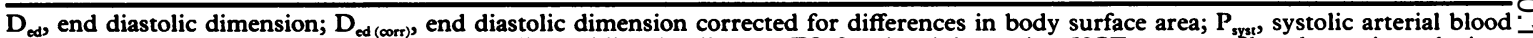

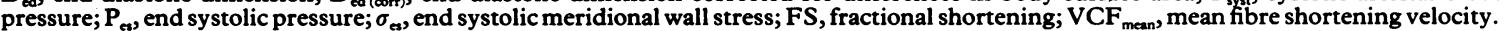

\section{Results}

\section{PATIENT DATA}

The mean (SD) age at the time of investigation was $16.7(5.4)$ and the age at the end of antineoplastic treatment was 12.1 (4.9). The mean (SD) cumulative dose of doxorubicin was $273(152) \mathrm{mg} / \mathrm{m}^{2}$ (range 31$656 \mathrm{mg} / \mathrm{m}^{2}$ ) (group 1, $120(42) \mathrm{mg} / \mathrm{m}^{2}$ (31-180 $\mathrm{mg} /$ $\left.\mathrm{m}^{2}\right)$; group 2, $278(74)\left(182-355 \mathrm{mg} / \mathrm{m}^{2}\right)$; group 3, 450 (70) $\mathrm{mg} / \mathrm{m}^{2}$ (363-656 $\left.\mathrm{mg} / \mathrm{m}^{2}\right)$. Five patients of the 55 patients had to be excluded from the study: one patient had an overt cardiomyopathy, two patients had raised blood pressure (in these three patients afterload challenge was not performed), and two patients had technically unsatisfactory echocardiograms.

\section{BASELINE HAEMODYNAMIC FUNCTION}

Table 1 shows the haemodynamic data at baseline conditions and table 2 shows the adjusted means according to analyses of covariance. Heart rates were significantly different in the various groups (analysis: of variance $p<0.01$ ), but after adjustment of the means for the age at investigation, analysis of ${ }^{\omega}$ covariance showed no difference (table 2 ). The end diastolic left ventricular dimension was significantly different in the various groups (analysis of variance $p<0.03$ ); again, this was because of the age at the time of investigation (table 2 ) and the associated differences of the body surface area. After correction $\mathbb{1}$ for body surface area $\left(D_{\text {ed(corr })}\right)$ the end systolic $\overrightarrow{0}$ dimension was similar in all the groups (table 1).

The end systolic wall stress was significantly higher in patients with a cumulative dose of doxorubicin of $>360 \mathrm{mg} / \mathrm{m}^{2}$ (analysis of covariance $\mathrm{p}<0.03$ ), whereas systolic, diastolic, mean, and end systolic arterial blood pressure were not significantly different in the various groups. No significant $\stackrel{\circ}{\rightarrow}$ differences of fractional shortening and mean fibre을 shortening velocity were seen between the groups.

Table 2 Baseline haemodynamic function (mean (SD)) with means adjusted for age at investigation and time since the end of antineoplastic treatment according to analysis of covariance

\begin{tabular}{|c|c|c|c|c|}
\hline & Group 1 & Group 2 & Group 3 & Control \\
\hline $\begin{array}{l}\text { Heart rate (beats/min) } \\
D_{\text {ed }} \\
\sigma_{\text {a }} \\
\text { FS } \\
\text { VCF }\end{array}$ & $\begin{array}{l}77(3 \cdot 7) \\
45(1 \cdot 1) \\
48(3 \cdot 6) \\
34(1 \cdot 1) \\
1 \cdot 2(0 \cdot 04)\end{array}$ & $\begin{array}{l}79(4 \cdot 3) \\
46(1 \cdot 3) \\
46(4 \cdot 3) \\
36(1 \cdot 2) \\
1 \cdot 3(0 \cdot 05)\end{array}$ & $\begin{array}{l}78(4 \cdot 0) \\
47(1 \cdot 2) \\
60(3 \cdot 9) \\
31(1 \cdot 1) \\
1 \cdot 1(0 \cdot 05)\end{array}$ & $\begin{array}{l}64(8 \cdot 0) \\
48(0 \cdot 5) \\
47(5 \cdot 9) \\
34(1 \cdot 8) \\
1 \cdot 1(0 \cdot 10)\end{array}$ \\
\hline
\end{tabular}

See footnote to table 1 for abbreviations.

Table 3 Indices (mean (SD)) of left ventricular systolic performance

\begin{tabular}{|c|c|c|c|c|}
\hline & Group 1 & Group 2 & Group 3 & Control \\
\hline $\begin{array}{l}P_{e s}-D_{e s} \\
\sigma_{e s}-F S \\
\sigma_{e s}-V C F\end{array}$ & $\begin{array}{c}72.9(24.9) \\
-0.204(0.05) \\
-0.57(0.27)\end{array}$ & $\begin{array}{l}53.2(19.9) \\
-0.258(0.05) \\
-0.84(0.24) \\
\text { time since end of }\end{array}$ & $\begin{array}{l}60.5(23.1) \\
-0.216(0.06) \\
-0.67(0.26)\end{array}$ & $\begin{array}{l}54 \cdot 1(18 \cdot 4) \\
-0.229(0.04) \\
-0.66(0 \cdot 14) \\
\text { lusis of covariance }\end{array}$ \\
\hline $\begin{array}{l}P_{e}-D_{e s} \\
\sigma_{e}-F S \\
\sigma_{e s}-V C F\end{array}$ & $\begin{array}{l}\text { Means adjusted for age at investigc } \\
\qquad \begin{array}{l}62 \cdot 2(5 \cdot 4) \\
-0.208(0.014) \\
-0.62(0.06)\end{array}\end{array}$ & $\begin{array}{l}\text { time since end of as } \\
45 \cdot 3(4 \cdot 9) \\
-0.257(0.016) \\
-0.83(0.07)\end{array}$ & $\begin{array}{l}51 \cdot 3(5 \cdot 3) \\
-0.212(0.015) \\
-0.62(0.06)\end{array}$ & \\
\hline
\end{tabular}

$\mathrm{P}_{\mathrm{es}}-\mathrm{D}_{\mathrm{es}}$, slope of the relation between end systolic left ventricular dimension and end systolic pressure; $\sigma_{\mathrm{es}}-\mathrm{FS}$, slope of the relation between end systolic wall stress and fractional shortening; $\sigma_{e s}-$ VCF, slope of the relation between end systolic wall stress and mean velocity of fibre shortening. 
Table 4 Indices (mean (SD)) of left ventricular diastolic function

\begin{tabular}{lcccc}
\hline & Group 1 & Group 2 & Group 3 & Control \\
\hline dDS-MO (\%) & $4 \cdot 7(3 \cdot 3)$ & $10 \cdot 8(8 \cdot 9)$ & $16 \cdot 7(10 \cdot 1)$ & $7 \cdot 4(6 \cdot 2)$ \\
dRF $(\%)$ & $66 \cdot 5(13 \cdot 7)$ & $58 \cdot 6(17 \cdot 5)$ & $51 \cdot 7(18 \cdot 9)$ & $62 \cdot 3(6 \cdot 2)$ \\
tDS-MO (ms) & $42 \cdot 1(34 \cdot 7)$ & $58 \cdot 5(24 \cdot 1)$ & $66 \cdot 5(32 \cdot 4)$ & $34 \cdot 9(21 \cdot 9)$ \\
VLR $_{\max }\left(\mathrm{s}^{-1}\right)$ & $3 \cdot 86(1 \cdot 06)$ & $3 \cdot 46(0.95)$ & $3.03(0 \cdot 92)$ & $4 \cdot 10(1 \cdot 23)$ \\
\hline
\end{tabular}

dDS-MO, change of dimension between minimal cavity dimension and mitral valve opening; dRF, change of dimension with rapid diastolic filling; $t D S-M O$, time between minimal cavity dimension and mitral valve opening; $V L R_{\max }$, maximal normalised fibre lengthening rate.

\section{LEFT VENTRICULAR SYSTOLIC PERFORMANCE}

The relations between end systolic pressure and dimension, end systolic wall stress and fractional shortening, and end systolic wall stress and mean fibre shortening velocity were linearly related in the normal subjects and patients, with linear regression coefficients ranging from 0.883 to 0.998 . The slopes for these relations were not significantly different in the patient groups and the control group (table 3).

\section{LEFT VENTRICULAR DIASTOLIC FUNCTION}

The change of dimension in the interval between minimal dimension and mitral valve opening (dDSMO) differed significantly between the groups (table 4) (analysis of variance $p<0.0001$, analysis of covariance $p<0.0004)$. It was significantly related to the cumulative dose of doxorubicin $(r=0.488)$. Similarly, the change of dimension with rapid diastolic filling (dRF) differed significantly between the groups (table 4) (analysis of variance $p<0.04$, analysis of covariance $p<0.01$ ) and was inversely related to the cumulative dose of doxorubicin $(r=-0.425)$. It changed less in patients with a cumulative dose of doxorubicin $>360 \mathrm{mg} / \mathrm{m}^{2}$ than in patients with a cumulative doxorubicin dose $<180$ $\mathrm{mg} / \mathrm{m}^{2}(\mathrm{p}<0.003)$. The time between minimal cavity dimension and mitral valve opening was slightly longer in patients with a cumulative dose of doxorubicin $>360 \mathrm{mg} / \mathrm{m}^{2}$ than in patients with a cumulative dose of doxorubicin $<180 \mathrm{mg} / \mathrm{m}^{2}$, but neither analysis of variance nor analysis of covariance showed significant differences between the groups (table 4). The maximal normalised fibre lengthening rate was similar in all the groups.

\section{Discussion}

Little is known about the long term changes of cardiac function after doxorubicin treatment. ${ }^{26}$ Because of the long life expectancy after successful antineoplastic treatment in childhood, evaluation of long term doxorubicin cardiotoxicity is important in this age group. ${ }^{1-427}$

Endomyocardial biopsy has become the reference standard for monitoring doxorubicin cardiotoxicity; none the less, histological grading has been shown to correlate poorly with left ventricular performance in most studies. ${ }^{6728}$ Left ventricular performance seems to be a more important indicator of toxicity than the histological appearance of the right ventricular myocardium. None of the patients we studied had received mediastinal irradiation or had overt cardiomyopathy.

\section{DIASTOLIC FUNCTION AFTER DOXORUBICIN TREATMENT}

Most studies of doxorubicin cardiotoxicity have focused on impaired left ventricular ejection. But diastolic function seems to be at least as important. ${ }^{15-17}$ We found that diastolic filling was significantly impaired after doxorubicin treatment in childhood. This impairment was related to the cumulative dose of doxorubicin (table 4) and was characterised by an impairment of rapid diastolic filling and an increased change of dimension between minimal cavity dimension and mitral valve opening.

In contrast with the isovolumic relaxation period, that is the interval between aortic valve closure and mitral valve opening, the interval between minimal cavity dimenion and mitral valve opening (tDS-MO) was independent of the timing of aortic valve closure and reflected the timing of mitral valve opening. The change of dimension in this period is usually small. ${ }^{23}$ An increase in the change of dimension between minimal cavity dimension and mitral valve opening reflects increased changes of left ventricular shape before mitral valve opening - that is incoordinate relaxation and impaired early diastolic function. Similarly, reduced early diastolic filling reflects impaired early diastolic function.

These alterations of diastolic filling could reflect restrictive endomyocardial disease, ${ }^{29}{ }^{30}$ as reported by Mortensen et al. ${ }^{15}$ Others have reported echocardiographic evidence of altered diastolic properties during antineoplastic treatment. ${ }^{16}{ }^{17}$ Our data indicate that impaired early diastolic function can persist at least for some years after the end of treatment.

\section{CONTRACTILE STATE AFTER DOXORUBICIN TREATMENT}

Recently, the slope of the end systolic pressurelength relation has been shown to be a load-independent and sensitive index of doxorubicin cardiotox- 

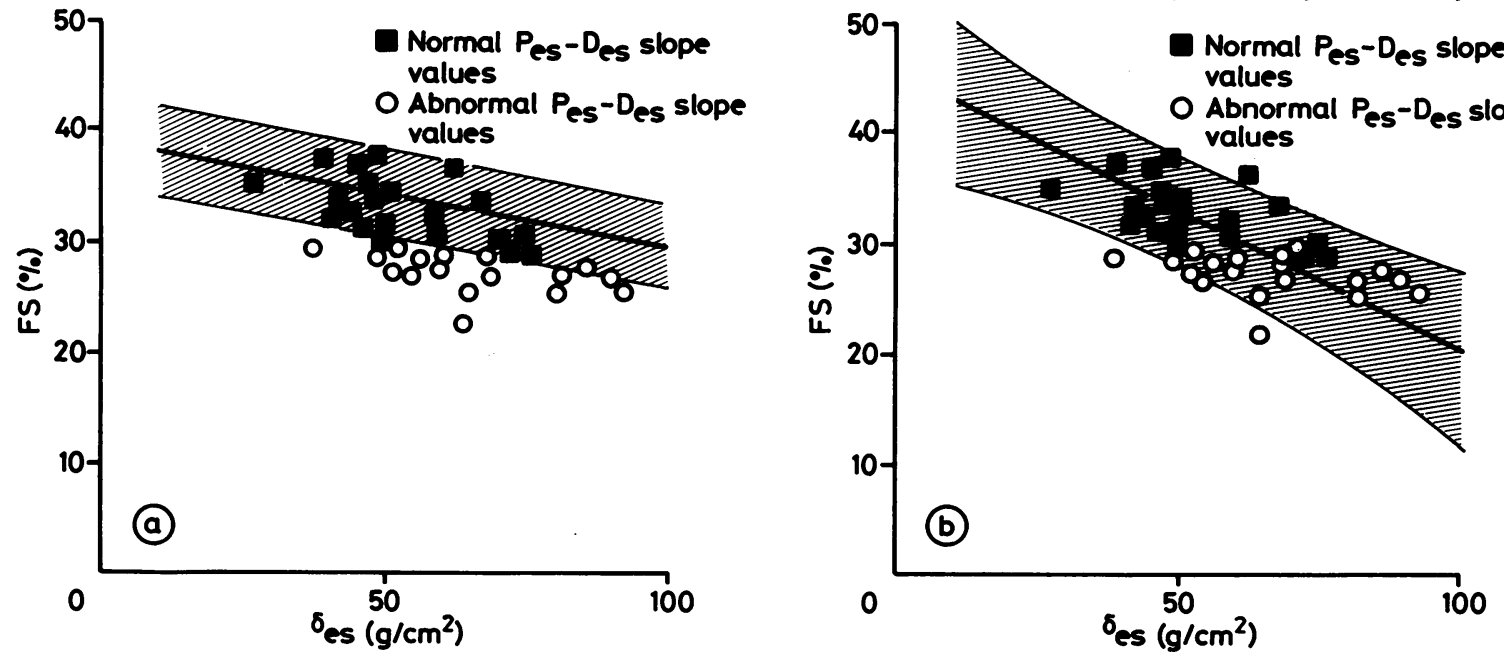

Fig 2 (a) Individual baseline values for end systolic wall stress and fractional shortening from a study by Borow et al ${ }^{10}$ and the normal range for the relation between end systolic wall stress $\left(\sigma_{s}\right)$ and fractional shortening $(F S)$ as defined by a afterload increase produced by methoxamine in normal subjects. ${ }^{10}$ The open circles are patients with an abnormal end systolic pressurelength relation $\left(P_{e s}-D_{e s}\right)$. (b) The same data points together with the normal range as defined by a afterload increase produced by angiotensin $1 I^{8}$ Most of the baseline stress-shortening data outside the normal range as defined by afterload increase with methoxamine are within the normal range as defined by angiotensin II.

icity. ${ }^{10}$ The end systolic stress shortening relations seem to be a more sensitive index than the pressurelength relation..$^{10}$ The end systolic stress-shortening relations reflect the interaction of forces working on the left ventricle at end ejection and the extent of fibre shortening. ${ }^{910}$

We found that doxorubicin treatment in childhood had no effect on end systolic pressure-length and stress-shortening relations $2 \cdot 1-10 \cdot 4$ years later. Surprisingly the contractile state was slightly increased in patients with a cumulative doxorubicin dose $<180$ $\mathrm{mg} / \mathrm{m}^{2}$. This could be the result of increased sympathetic drive because unlike the normal subjects these patients knew that they were being investigated for possible heart disease.

End systolic wall stress during baseline conditions was significantly increased in patients in whom the cumulative dose of doxorubicin was $>360 \mathrm{mg} / \mathrm{m}^{2}$. This increase reflects an increased afterload ${ }^{31}$ (tables 1 and 2). This result accords with the data reported by Borow et al, who showed that the baseline values of end systolic wall stress and fractional shortening predicted the contractile state after doxorubicin treatment $^{10}$ (fig 2). But unlike these workers we increased afterload with angiotensin $\mathrm{II}^{8}$ not methoxamine ${ }^{10}$; this resulted in a different normal range with steeper gradients for the end systolic pressure-length and stress-shortening relations. ${ }^{8}$ Angiotensin II has negligible effects on preload, unlike methoxamine, and this difference may have influenced the end systolic pressure-length and stress-shortening relations in these two studies.
Most baseline data for stress-shortening relation $\varsigma^{\circ}$ that were outside the normal range after the afterloa 8 was increased with methoxamine (fig 2a) were withif the normal range for studies in which the afterloag was increased by angiotensin II in normal subjectro (fig 2). ${ }^{810}$ Although it is normal for systolic emptyin 8 to be reduced and end systolic wall stress to ber increased when the afterload is increased, ${ }^{31}$ a sig nificant increase in end systolic wall stress during baseline conditions is definitely abnormal. So the measurement of the end systolic wall stress during baseline conditions may be an important method of monitoring doxorubicin cardiotoxicity.

Our data show that diastolic function is signifio cantly altered after doxorubicin treatment in child hood. Impaired diastolic function was seen in patients without overt cardiomyopathy and was related to the cumulative dose of doxorubicin. It may be that impairment of left ventricular diastolic func? tion is related to restrictive endomyocardial disease. We did not, however, find that the contractile state was significantly impaired (that is, doxorubicin had no effect on the end systolic pressure-length an $\$$ stress-shortening relations). None the less, a sig nificant increase of the end systolic wall stress during baseline conditions in patients with high cumulative doxorubicin dose showed that the afterload was increased after doxorubicin treatment in childhood:

\section{References}

1 Young RC, Ozols RF, Myers CE. The anthracyclin antineoplastic drugs. N Engl J Med 1981;305:139-5远 
2 Pratt CB, Ransom JL, Evans WE. Age-related adriamycin cardiotoxicity in children. Cancer Treat $\operatorname{Rep~1978;62:1381-5.~}$

3 Goorin AM, Borow KM, Goldman A, et al. Congestive heart failure due to adriamycin cardiotoxicity: its natural history in children. Cancer 1981;47:2810-6.

4 Gilladoga AC, Manuel C, Tan CTC, Wollner N, Sternberg SS, Murphy ML. The cardiotoxicity of adriamycin and daunomycin in children. Cancer 1976;37:1070-8.

5 Billingham ME, Mason JW, Bristow MR, Daniels JR. Anthracycline cardiomyopathy monitored by morphologic changes. Cancer Treat Rep 1978;62:865-72.

6 Mason JW, Bristow MR, Billingham ME, Daniels JR. Invasive and non-invasive methods of assessing adriamycin cardiotoxic effects in man: superiority of histopathologic assessment using endomyocardial biopsy. Cancer Treat Rep 1978;62:857-64.

7 Bristow MR, Mason JW, Billingham ME, Daniels JR. Doxorubicin cardiomyopathy: evaluation by phonocardiography, endomyocardial biopsy, and cardiac catheterization. Ann Intern Med 1978;88:168-75.

8 Hausdorf G, Gluth J, Nienaber CA. Non-invasive assessment of end-systolic pressure-length and stress-shortening relationships in normal individuals: significance of different loading conditions induced by methoxamine and angiotensin II. Eur Heart J 1987;8:1099-108.

9 Borow KM, Green LH, Grossman W, Braunwald E. Left ventricular end-systolic stress-shortening and stress-length relations in humans. Am J Cardiol 1982;50:1301-8.

10 Borow KM, Henderson IC, Neuman A, et al. Assessment of left ventricular contractility in patients receiving doxorubicin. Ann Intern Med 1983;99:750 6.

11 Colan SD, Borow KM, Neumann A. Left ventricular end-systolic wall stress velocity of fiber shortening relation: a load independent index of myocardial contractility. J Am Coll Cardiol 1984;4:715-24.

12 Sagawa K, Suga H, Shoukas AA, Bakalar KM. Endsystolic pressure/volume ratio: a new index of ventricular contractility. Am J Cardiol 1977;40:748-53.

13 Sagawa K. The end-systolic pressure-volume relation of the ventricle: definition, modifications and clinical use. Circulation 1981;63:1223-7.

14 Weber KT, Janicki JS. The dynamics of ventricular contraction: force, length, and shortening. Fed Proc 1980;39:188-95.

15 Mortensen SA, Olsen HS, Baandrup U. Chronic anthracycline cardiotoxicity: haemodynamic and histopathological manifestations suggesting a restrictive endomyocardial disease. Br Heart $J$ 1986;55:274-82.

16 Stein E, Hanrath P, Bleifeld W, Garbrecht M, Muellerleile U. Abnormales Kontraktions- und Füllverhalten des linken Ventrikels bei Tumorpatienten unter Adriamycin-Therapie. $D M W$ 1978;103:1408.

17 Goldberg SJ, Hutter JJ, Feldman L, Goldberg SM.
Two sensitive echocardiographic techniques for detecting doxorubicin toxicity. Med Pediatr Oncol 1983;11:172-7.

18 Sahn DJ, DeMaria A, Kissio J, Weyman A. The committee on $\mathrm{M}$-mode standardization of the American Society of Echocardiography. Recommendations regarding quantification in $\mathbf{M}$-mode echocardiography: results of a survey of echocardiographic measurements. Circulation 1978;58:1072-83.

19 Borow KM, Newburger JW. Non-invasive estimation of central aortic pressure using the oscillometric method for analyzing systemic artery pulsatile blood flow: comparative study of indirect systolic, diastolic, and mean brachial artery pressure with simultaneous direct ascending aortic pressure measurements. $\mathrm{Am}$ Heart J 1982;103:879-86.

20 Stefadouros MA, Dougherty MJ, Grossman W, Craig E. Determination of systemic vascular resistance by a non-invasive technique. Circulation 1973;47:101-7.

21 Borow KM, Arensman FW, Webb C, Radley-Smith R, Yacoub MH. Assessment of left ventricular contractile state after anatomic correction of transposition of the great arteries. Circulation 1984;69:106-12.

22 Brodie BR, McLaurin LP, Grossman W. Combined hemodynamic-ultrasonic method for studying left ventricular wall stress: comparison with angiography. Am J Cardiol 1976;37:864-70.

23 Upton MT, Gibson DG. The study of left ventricular function from digitized echocardiograms. Prog Cardiovasc Dis 1978;20:359-84.

24 Chen W, Gibson DG. Relation of isovolumic relaxation to left ventricular wall motion in man. Br Heart J 1979;42:51-6.

25 Hanrath P, Mathey DG, Siegert R, Bleifeld W. Left ventricular relaxation and filling pattern in different forms of left ventricular hypertrophy. Am J Cardiol 1980;45:15-23.

26 Gottdiener JS, Mathisen DJ, Borer JS, et al. Doxorubicin cardiotoxicity: assessment of late left ventricular dysfunction by radionuclide cineangiography. Ann Intern Med 1981;94:430-5.

27 Pegelow CH, Popper RW, de Wit SA, King OY, Wilbur JR. Endomyocardial biopsy to monitor anthracycline therapy in children. J Clin Oncol 1984;2:443-6.

28 Ewer MS, Khalil A, Mackay B, et al. A comparison of cardiac biopsy grades and ejection fraction estimations in patients receiving adriamycin. J Clin Oncol 1984;2:112-7.

29 Hausdorf G, Grävinghoff L, Sieg K, Keck EW. Echocardiographic characteristics of diastolic dysfunction in restrictive cardiomyopathy in childhood. $J$ Am Coll Cardiol 1955;5:528.

30 Tyberg TI, Goodyer BVN, Hurst VW, Alexander J, Langou RA. Left ventricular filling in differentiating restrictive amyloid cardiomyopathy and constrictive pericarditis. Am J Cardiol 1981;47:791-6.

31 Lang RM, Borow KM, Neumann A, Janzen D. Systemic vascular resistance: an unreliable index of left ventricular afterload. Circulation 1986;74:1114-23. 